\title{
O Vestibular EM DISCUSSÃO ${ }^{1}$
}

\section{ZÉLIA HERINGER DE Moraes"}

As provas objetivas foram introduzidas nos concursos vestibulares quando estes passaram a ser realizados para um grande número de estudantes. Tomando por base a experiência desenvolvida nos Estados Unidos da América do Norte na utilização de provas objetivas padronizadas para a avaliação do ensino, decidiu-se por esse instrumento de seleção porque sua correção seria isenta de viés, mais rápida e, quando bem elaborada, selecionaria estudantes com boa formação geral.

Com o tempo, a proposta inicial de exame vestibular foi sofrendo modificações, desde a composição do número de provas e de itens, até a realização do exame em duas fases: a primeira composta de itens de múltipla escolha e eliminatória, e a segunda composta por questões dissertativas e de redação, somente classificatória.

A par dessas modificações na forma, existia a carência de técnicos especializados em medidas educacionais que pudessem assessorar o exame e avaliar a influência dos diferentes tipos de provas no processo seletivo.

Estes mesmos princípios se aplicavam à prova de língua portuguesa, onde se procurava verificar, através de diferentes

'Resumo da tese de mestrado da Faculdade de Educaşáo da Universidade de Săo Paulo, 1992.

- Psicometrista II da Fundaçito Carlos Chagas. 
propostas de questões de múltipla escolha, o conhecimento da língua possuído pelo candidato.

O aprendizado das regras gramaticais básicas para a obediência da chamada "norma culta" na comunicação oral e escrita das pessoas é considerado o maior objetivo da escolarização formal. Daí o peso da prova de Língua Portuguesa nos concursos vestibulares.

A lei $n^{0} 5692$ de 1971 , em seu artigo quarto, parágrafo segundo, coloca que "no ensino de primeiro e segundo graus dar-se-á especial relevo ao estudo da língua nacional, como instrumento de comunicação e expressão da cultura brasileira.

O parecer CEF $n^{\circ} 4031 / 75$ denuncia uma crise na linguagem dos candidatos, atribuída, entre outros fatores, à influência do uso de testes de múltipla escolha no vestibular sobre a formação do estudante de segundo grau. Como solução propunha a utilização da redação a partir de 1976.

A Portaria CEF de no 53 de 23 de janeiro de 1975 recomendava o uso do escore padronizado na avaliação das provas.

O Decreto $\mathrm{n}^{0} 79298 / 77$ propunha a utilização de um novo tipo de vestibular com a inclusão de prova ou questão de redação em Língua Portuguesa; instituiu a possibilidade da realização do vestibular em mais de uma etapa; introduziu provas de habilitação específica para determinados cursos e um escore mínimo de aprovação. Segundo Lellis (1985), este modelo era eliminatório e classificatório, indicando um retorno do exame vestibular ao papel de verificador de habilitação.

A Portaria $\mathrm{n}^{\mathrm{0}} 322$ (02 de junho de 1977) definiu o que seria etapa para o exame (qualquer prova ou conjunto de provas) e o que seria entendido como nível mínimo de conhecimento (mínimo de pontos por prova ou pelo total das provas).

Já a Portaria Ministerial $\mathrm{n}^{\mathrm{0}} 231$ de 16 de maio de 1980 estabelecia que o sistema de provas deveria valorizar o idioma nacional, regionalizar os vestibulares na medida do possível, trabalhar o nível de dificuldade das provas compatível com o do segundo grau, dar à redação peso igual ou superior ao das demais provas ou questões do exame e aconselhava a utilização de especialistas em medidas educacionais na elaboração das provas. 
Academicamente justificou-se a inclusão da redação pela necessidade de o candidato comprovar domínio da capacidade escrita, requisito para um bom desempenho nos estudos universitários. Esta medida também foi criticada por não garantir um melhor desempenho lingüístico dos candidatos aprovados, dado que este seria explicado por fatores socioeconômicos e sócio-culturais.

Pela Portaria no 380 de 29 de maio de 1986 , tem-se que "a aferição do conhecimento do idioma nacional deverá incluir prova ou questão de redação em Língua Portuguesa, ressaltando-se a capacidade de síntese e de análise do vestibulando...".

O Decreto $\mathrm{n}^{\circ} 96533$ de 17 de agosto de 1988 determinava que a prova de redação passasse a ter caráter eliminatório, independente da área, curso ou habilitação de opção do candidato.A legislação posterior manteve essas mesmas características até 1990.

A colocação de uma prova de redação no concurso vestibular partiu do pressuposto que, além de aferir o conhecimento da língua, ela poderia vir a exercer influência sobre o ensino de segundo grau, na medida em que agia contra o treinamento em respostas para questões objetivas e desenvolvia o pensamento analítico e a capacidade de relacionar dos estudantes. Mas o que de fato aconteceu foi que o treinamento em redação, nas escolas de segundo grau e nos cursinhos preparatórios ao vestibular, passou a ser feito com aberturas e fechamentos dados pelos professores e decorados pelos estudantes .

Por outro lado, a adoção desta prova introduziu a dificuldade da correção nos concursos vestibulares ja que essa correção passou a depender do julgamento de professores avaliadores, comprometendo os princípios de isonomia e isenção de julgamento pessoal. Além disso, o procedimento de correção de redações, dado a seus controles técnicos, ficou extremamente caro. A influência esperada da prova de redação no vestibular sobre o ensino da língua não ocorreu.

Muitos estudos passaram a ser feitos, a partir de 1976, sobre o problema da redação e sua correção (Vianna: 1976, 1978, 1980, 1981, 1982, 1987; Moraes, 1987), sobre o estabelecimento de uma escala que auxiliasse na correção de redações e sobre a utilização do método impressionista e/ou do método analítico para se obter uma maior fidedignidade de correção entre os avaliadores (como exemplo de literatura especializada neste assunto ver Hoffman, 1988) 
Por outro lado, o conhecimento sistematizado da língua portuguesa por parte da população aprovada no exame deixava a desejar. Rocco (1981), analisando 1600 redações de vestibulandos já aprovados para realizarem a segunda fase de um concurso vestibular, concluiu que tanto no nível entre frases como também no nível intrafrase e no contexto da redação como um todo, a linguagem dos vestibulandos apresentou-se como não-coesiva $\mathrm{e}$ incoerente, devido à falta de nexos lógicos e à utilização de clichês e frases feitas. Também concluiu que redigem mal os alunos de escolas públicas e de escolas particulares, independentemente de terem ou não freqüentado um "cursinho" preparatório ao exame.

\section{COLOCAÇão do Problema}

$\mathrm{Na}$ década de 30, nos Estados Unidos, Sims (1931) apresentou os resultados de um estudo que envolvia atribuição de notas para duas formas paralelas de questões dissertativas e um teste objetivo sobre o mesmo conteúdo. Neste trabalho, definia como objetividade de uma avaliação, a extensão na qual juízes competentes concordam quanto à nota de uma prova; como fidedignidade da nota atribuída, a consistência do desempenho do estudante; e como validade, a extensão pela qual a questão dissertativa avalia o mesmo conteúdo que a prova objetiva sobre o mesmo assunto. Conclui o autor que a existência de uma alta concordância entre a questão aberta e a prova objetiva podia ser interpretada como significando que a prova objetiva é um instrumento de medida melhor do que a prova dissertativa.

Di Dio (1978) estudando provas compostas de questões analítico-dissertativas em um concurso vestibular, conclui, entre outras coisas, que a correlação entre as duas provas foi boa para todas as áreas de estudo, com exceção da área de Comunicação e Expressão, talvez devido ao fato de pessoas diferentes terem corrigido as redações e esta correção envolver maior grau de subjetividade.

Vianna (1981), no trabalho "Medida da Expressão Escrita e Prova Objetiva: um estudo preliminar de validade", visou a determinar o grau de concordância entre os escores obtidos na prova de Comunicação e Expressão e os escores coletados de sujeitos em uma dissertação "que supostamente mede a capacidade de expressão 
escrita" (pg 29). Ainda segundo o autor, sua pesquisa procurou estabelecer a relação entre o desempenho de um grupo de sujeitos em uma prova objetiva de Comunicação e Expressão e o desempenho dos mesmos sujeitos em uma prova dissertativa. Tendo definido o seu propósito, o autor desenvolveu o trabalho no sentido de estabelecer a validade desta prova.

A amostra da pesquisa de Vianna foi constituída de 161 indivíduos de diferentes áreas de opção na área biomédica que prestaram o vestibular realizado pelo CESCEM, em janeiro de 1975. Os resultados foram apresentados conforme se segue: primeiro, quanto à análise das características da prova objetiva; segundo, quanto às características da prova de redação e, por fim, quanto às estatísticas de validação da prova de Comunicação e Expressão.

Metodologicamente estabeleccu, com um grupo de docentes qualificados, qual seria a definição operacional do termo "capacidade de expressão escrita" que seria utilizada para a montagem da prova objetiva e como critério de correção da prova dissertativa. A prova objetiva de Comunicação e Expressão visou a verificar as seguintes capacidades: uso ativo do sistema linguístico; domínio das normas da língua; identificação dos recursos estilísticos da língua e compreensão da idéia fundamental de um texto. Para a prova de redação foram fixados alguns princípios orientadores para a correção: estrutura geral (organicidade do texto e unicidade); estrutura interna (metodologia do texto); conteúdo (necessidade do texto, coerência interna, concentração e síntese, pensamento divergente, individualidade); expressão (propriedade do vocabulário- léxico, correção gramaticalortografia, pontuação, morfologia e sintaxe).

Os resultados, segundo Vianna, demonstram que existe concordância entre o desempenho na prova objetiva de Comunicação e Expressão e o desempenho na redação, ou seja, "a prova objetiva de Comunicação e Expressão mede de modo significante o que é igualmente medido pela prova de redação...."(Vianna, 1981, p.38).

$O$ autor afirma que:

"os coeficientes de validade refletem a capacidade de expressão escrita, conforme anteriormente definida de modo operacional. Ressalte-se, entretanto, que os coeficientes de validade referem-se ao grupo amostral e à presente prova, e poderão ser alterados caso o 
instrumento seja empregado em um grupo diverso do amostral e modificados os objetivos da prova..."(Vianna, 1981, p.39).

\section{OBJETIVO}

O presente trabalho tem por objetivo correlacionar o desempenho de candidatos em um concurso de ingresso à universidade, em prova de múltipla escolha e em prova de redação na disciplina de Língua Portuguesa, de modo a se verificar a validade concorrente das referidas provas.

\section{PROCEDIMENTO}

Foram estudadas as provas de um concurso vestibular planejado, elaborado, corrigido e analisado pela Fundação Carlos Chagas para uma universidade estadual no ano de 1988.

Foram estabelecidos os seguintes procedimentos:

1. separou-se a folha de resposta das questões de múltipla escolha e a folha de redação correspondente, da prova de Comunicação e Expressão, de uma amostra casual de 5\% dos candidatos presentes ao concurso vestibular, estratificada por área de opção. Dos 7004 inscritos, obteve-se uma amostra casual estratificada de 373 sujeitos.

2. do conjunto de 50 questões de múltipla escolha que compunham a prova, foram eliminadas 15 questões referentes ao conteúdo de Literatura Brasileira, dado que ao presente estudo importava apenas o domínio da língua como instrumento de comunicação. Assim, a prova passou a ter 35 questões. A seguir, esta nova versão da prova foi corrigida e suas questões foram analisadas estatisticamente. A análise estatística possibilitou:

- a ordenação decrescente dos escores e a constituição de 3 subgrupos: grupo superior e grupo inferior, cada um deles composto de $27 \%$ dos elementos do grupo total e os $46 \%$ restantes compondo o grupo médio.

- a formação de uma matriz de resposta para cada questão, de modo a se obter o índice de dificuldade (porcentagem do grupo total que acertou a questão) e o índice de discriminação (permite dizer se a 
questão separou os candidatos do grupo superior daqueles do grupo inferior).

3. desidentificação do nome e da nota de cada redação e correção independente da mesma por 3 professores treinados, utilizando uma ficha de atribuição de nota por redação.

\section{I - Composição da população estudada por área de opção e curso}

\begin{tabular}{|c|c|c|c|c|}
\hline AREA & CURSO & POP & AMOSTRA & $\%$ \\
\hline Clências Biológlcas & $\begin{array}{l}\text { Clências Blologicas } \\
\text { Enfermagem } \text { O Obstetricia } \\
\text { Famácia } \\
\text { Fisloterapla } \\
\text { Medtcina } \\
\text { Mediclna Veterinária } \\
\text { Odontologia } \\
\text { Psicologia } \\
\text { Total }\end{array}$ & $\begin{array}{r}161 \\
100 \\
327 \\
229 \\
650 \\
432 \\
519 \\
156 \\
2574 \\
\end{array}$ & $\begin{array}{r}9 \\
9 \\
12 \\
16 \\
33 \\
30 \\
24 \\
11 \\
140 \\
\end{array}$ & $\begin{array}{l}5.59 \\
5.00 \\
3.66 \\
6.98 \\
5.07 \\
6.54 \\
4.62 \\
7.05 \\
5.44 \\
\end{array}$ \\
\hline Clênclas Humanas & 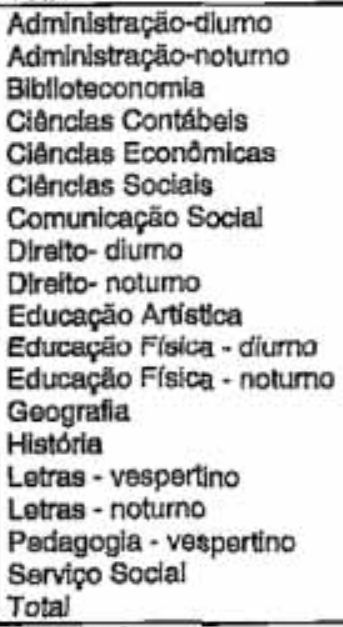 & $\begin{array}{c}181 \\
448 \\
65 \\
316 \\
188 \\
128 \\
221 \\
385 \\
647 \\
79 \\
86 \\
142 \\
85 \\
132 \\
48 \\
185 \\
92 \\
78 \\
3517 \\
\end{array}$ & $\begin{array}{c}13 \\
27 \\
5 \\
16 \\
9 \\
4 \\
12 \\
22 \\
30 \\
5 \\
3 \\
7 \\
6 \\
6 \\
1 \\
9 \\
2 \\
5 \\
182 \\
\end{array}$ & $\begin{array}{l}7.18 \\
6.02 \\
7.69 \\
5.06 \\
4.78 \\
3.12 \\
5.42 \\
5.71 \\
4.63 \\
6.32 \\
3.48 \\
4.92 \\
7.05 \\
4.54 \\
2.04 \\
4.61 \\
2.17 \\
6.41 \\
5.17 \\
\end{array}$ \\
\hline Clências Exatas & $\begin{array}{l}\text { Agronomia } \\
\text { Arquitetura } \\
\text { Engenharia } \\
\text { Fisica } \\
\text { Matemática } \\
\text { Quimica } \\
\text { Total } \\
\end{array}$ & $\begin{array}{c}355 \\
89 \\
211 \\
69 \\
146 \\
43 \\
913 \\
\end{array}$ & $\begin{array}{c}19 \\
2 \\
14 \\
4 \\
11 \\
1 \\
51 \\
\end{array}$ & $\begin{array}{l}5.35 \\
2.24 \\
6.63 \\
5.79 \\
7.53 \\
2.32 \\
5.58 \\
\end{array}$ \\
\hline & Total Geral & 7.004 & 373 & 5.32 \\
\hline
\end{tabular}

Pela tabela acima tem-se que cada área foi representada por cerca de $5 \%$ dos sujeitos, sendo que o total da população foi amostrado em $5.32 \%$. 
Embora o estudo de Vianna (1981) apenas investigasse os candidatos da área biológica, decidiu-se trabalhar com uma amostra representativa de todas as áreas.

\section{II- Composição da amostra por sexo e área de opção}

\begin{tabular}{|c|c|c|c|c|}
\hline $\begin{array}{c}\text { Sexo } \\
\text { Área }\end{array}$ & $\begin{array}{c}\text { Masculino } \\
\text { N }\end{array}$ & $\begin{array}{c}\text { Masculino } \\
\%\end{array}$ & $\begin{array}{c}\text { Feminino } \\
\text { N }\end{array}$ & $\begin{array}{c}\text { Feminino } \\
\text { \% }\end{array}$ \\
\hline Ciências Biológicas & 49 & 13.13 & 91 & 24.39 \\
\hline Ciências Humanas & 87 & 23.32 & 95 & 25.46 \\
\hline Ciências Exatas & 34 & 9.11 & 17 & 4.57 \\
\hline Total & 170 & 45.57 & 203 & 54.42 \\
\hline
\end{tabular}

Do total de candidatos amostrados, 45.57 cram do sexo masculino e 54.42 do sexo feminino. Ainda em relação ao total de candidatos, a população masculina inscrita nas áreas de ciências biológicas, ciências humanas e ciências exatas era de 13.13; 23.32 e 9.11 , respectivamente. Na população feminina estes totais passam a ser de $24.34 ; 25.46$ e 4.5 , respectivamente.

A descrição da amostra por ano de nascimento e área de opção é a seguinte:

\section{III- Distribuição de freqüência de candidatos segundo o ano de nascimento e área de opção (em \%)}

\begin{tabular}{|c|c|c|c|c|}
\hline Area de opção & $\begin{array}{c}\text { Ciências } \\
\text { Biológicas }\end{array}$ & $\begin{array}{c}\text { Ciências } \\
\text { Humanas }\end{array}$ & $\begin{array}{c}\text { Ciências } \\
\text { Exatas }\end{array}$ & Total \\
\hline$<$ Ano de nascimento & 0.54 & 6.43 & - & 6.97 \\
\hline $1960-1962$ & 1.33 & 2.40 & 0.80 & 4.55 \\
\hline $1963-1965$ & 2.95 & 9.38 & 1.33 & 13.67 \\
\hline $1966-1968$ & 14.74 & 14.21 & 3.21 & 32.43 \\
\hline $1969-1971$ & 17.96 & 16.35 & 8.31 & 42.62 \\
\hline Total & 37.53 & 48.79 & 13.94 & 100 \\
\hline
\end{tabular}

A tabela permite afirmar que, em relação ao total da amostra, a maioria dos candidatos ( 42.62 e 32.43 perfazendo um total de 75.05 ) possuía entre 17 e 22 anos, respectivamente. Também é interessante perceber que $6.43 \%$ da população mais velha inscreveu-se na área de 
Ciências Humanas. Os candidatos mais jovens inscreveram-se, em sua maioria, em Ciências Biológicas (17.96 e 14.74) e em Ciências Humanas (16.35 e 14.21).

Analisando a amostra segundo seu desempenho final no Concurso, por área de opção, tem-se os seguintes dados:

IV-Classificados e não classificados por área de opção ( em \%)

\begin{tabular}{|c|c|c|c|c|}
\hline $\begin{array}{c}\text { Área de opção } \\
\text { resultado }\end{array}$ & $\begin{array}{c}\text { Ciências } \\
\text { Biologicas }\end{array}$ & $\begin{array}{c}\text { Ciências } \\
\text { Humanas }\end{array}$ & $\begin{array}{c}\text { Ciências } \\
\text { Exatas }\end{array}$ & Total \\
\hline classificado & 30.83 & 34.31 & 5.09 & 70.24 \\
\hline não classificado & 6.70 & 14.47 & 8.58 & 29.75 \\
\hline Total & 37.53 & 48.79 & 13.94 & 100 \\
\hline
\end{tabular}

Pela tabela tem-se que a amostra, em sua maioria (70.24), estaria composta de aprovados e classificados no exame vestibular. Observa-se ainda que apenas na área de Ciências Exatas, a porcentagem de não classificados (8.58) supera a de classificados (5.09). Na área de Ciências Biológicas, o número de não classificados (6.70) é bastante inferior ao de classificados (30.83), enquanto que na de Ciências Humanas essa diferença é menor (14.47 não classificados e 34.31 classificados).

Os critérios para definir um candidato como classificado ou não classificado foram os mesmos usados pela universidade estudada, conforme estabelecido no manual recebido pelos candidatos:

"serão passíveis de classificação apenas os candidatos que:

a) tenham comparecido a todas as provas constantes do concurso vestibular;

b) tenham alcançado nota diferente de zero em cada uma das provas;

c) no cômputo geral das provas objetivas, acertem, no mínimo, $25 \%$ dos itens;

d) acertem, no mínimo, $25 \%$ dos itens da prova de conhecimento do curso optado, quais sejam:

1) área de Ciências Biologicas: no conjunto das provas de Química e Biologia;

2) área de Ciências Humanas: na prova de Estudos Sociais;

3) área de Ciências Exatas: no conjunto das provas de Matemática e Física. 


\section{Analisando a Prova ObJettva}

Para a análise da prova, o gráfico apresentado a seguir fornece informações interessantes para uma discussão. A parte esquerda mostra as 35 questões que compuseram a prova e, para cada uma, o número de candidatos que acertaram a questão. A média do grupo foi de 16.07 acertos, com um desvio padrão de 5.99. As notas limites inferior e superior desta distribuição foram 11 e 19 acertos, respectivamente. Calculando-se a mediana obtém-se o valor de 14.53 . A distribuição é multimodal, sendo que os valores mais marcantes da moda foram 11 e 15 acertos. Ela é também assimétrica positiva, indicando uma prova relativamente difícil para a população amostrada.

\section{V- Análise por itens Distribuição de Notas Prova de Comunicação e Expressão}

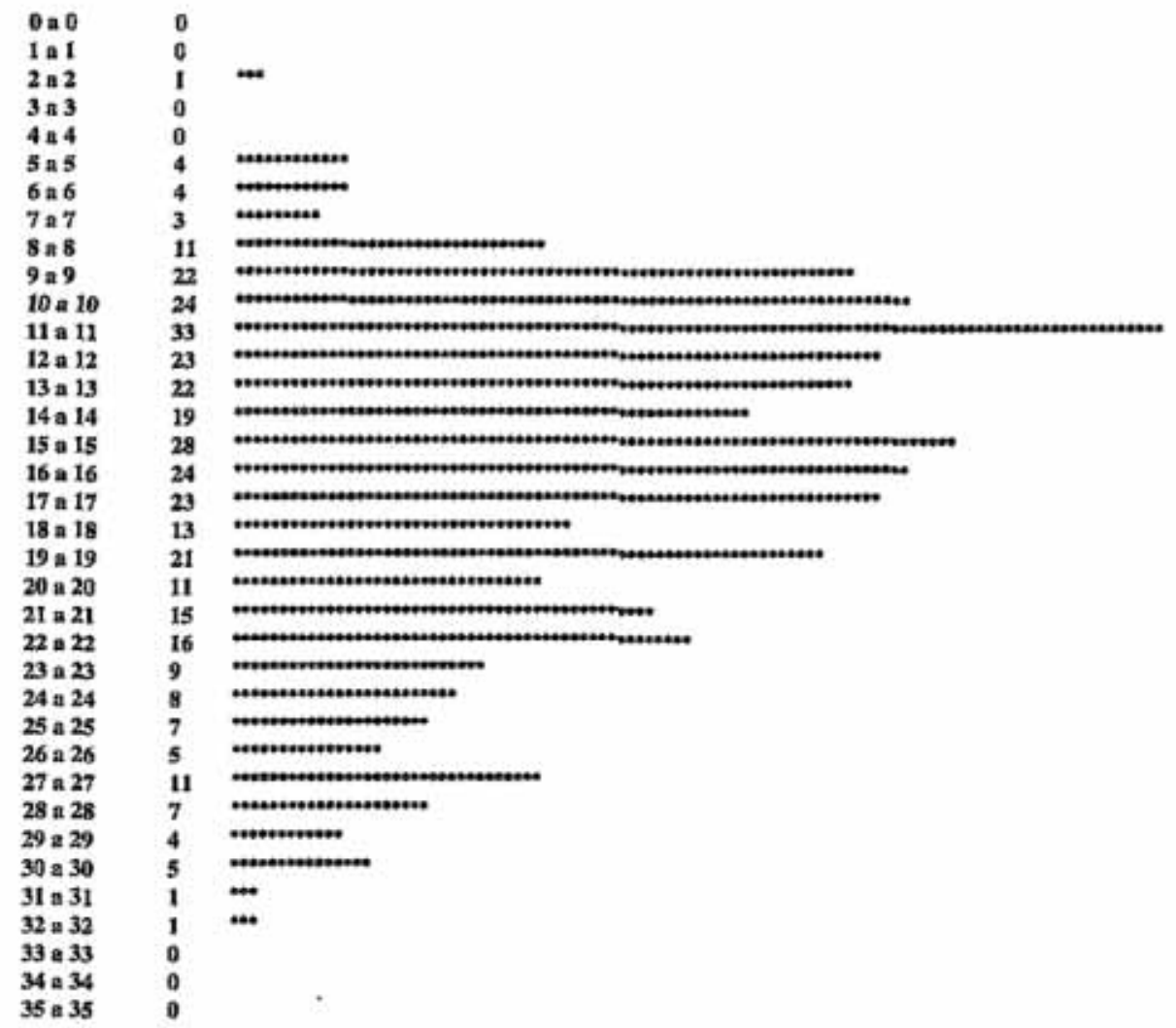

373 candidatos presentes na amostra

Nota limite inferior 11 Nota limite superior 19

Média 16.07 Desvio Padräo 5.99 
No gráfico tem-se ainda que a amplitude total dos escores foi de 30 questões (de 32 a 2 acertos). Acima da média se situaram 157 candidatos e, abaixo, 216.

Analisando os itens que compuseram a prova, segundo seu grau de facilidade, encontraram-se os dados apresentados abaixo:

VI- Distribuição dos valores brutos e percentuais de acertos

\begin{tabular}{|c|c|c|c|}
\hline Classificação & $\begin{array}{c}\text { Porcentagem de } \\
\text { acerto }\end{array}$ & F & \% \\
\hline Muito Fácil & $95-100$ & - & $\cdot$ \\
$85-94$ & - & - \\
\hline Fácil & $75-84$ & 2 & 5.71 \\
& $65-74$ & 3 & 8.57 \\
\hline Médio & $55-64$ & 5 & 14.28 \\
& $45-54$ & 10 & 28.57 \\
& $35-44$ & 6 & 17.13 \\
\hline Diffcil & $25-34$ & 4 & 11.42 \\
& $15-24$ & 5 & 14.28 \\
\hline Muito Difícil & $0-14$ & - & - \\
\hline
\end{tabular}

Os dados da Tabela indicam que os itens não foram "muito fáceis" ou "muito diff́ceis" para o grupo em foco. Dos itens, 5 (14.28\%) foram considerados "fáceis", 21 itens (60\%) de dificuldade "média"e 9 itens $(60 \%)$ de dificuldade "média"e 9 itens $(25.71 \%)$ foram "difíceis" para o grupo que compôs a amostra.

As categorias muito fácil, fácil, médio, difícil e muito difícil foram montadas baseadas no já citado trabalho de Vianna (1986). Itens considerados muito fáceis incluíram dois intervalos de acerto 85-94 e 95-100. Os fáceis abrangiam as percentagens de acerto de 75-84 e 65- 
74. Itens de dificuldade média envolviam categorias de acerto que eram de 55-64, 45-54 e 35-44. Itens difíceis encaixam-se nas categorias 25-34 e 15-24 e itens muito difíceis se localizaram na categoria de 0 a 14.

Da mesma forma, Vianna (1986) criou categorias que classificassem os coeficientes de discriminação. Estas categorias encontram-se apresentadas a seguir:

VII-Distribuição das freqüências absolutas e percentuais dos coeficientes de discriminação

\begin{tabular}{|c|c|c|c|}
\hline Classificaçäo & $\begin{array}{c}\text { Coeficiente de } \\
\text { discriminaçäo }\end{array}$ & f & $\%$ \\
\hline excelentes & 0.80 & - & - \\
\hline ótimos & $0.60-0.79$ & 6 & 17.14 \\
\hline muito bons & $0.40-0.59$ & 21 & 60 \\
\hline bons & $0.20-0.39$ & 6 & 17.14 \\
\hline fracos & $0.10-0.19$ & 1 & 2.85 \\
\hline muito fracos & $0.00-0.9$ & 1 & 2.85 \\
\hline N & & 35 & 100 \\
\hline
\end{tabular}

Dos itens que compuseram a prova, apenas dois tiveram índices de discriminação fraco ou muito fraco.

Segundo Vianna (1981), considera-se um bom índice de discriminação de 0.40 ou mais. De $0.30-0.39$ o índice é considerado bom mas sujeito a aprimoramento; um índice de 0.20-0.29 é um índice marginal sujeito a reelaboração e um índice de 0.19 é considerado defíciente e deve ser rejeitado. A prova em questão teve $77.14 \%$ dos itens com índice acima de 0.40 . Portanto, pode-se concluir que a prova de Comunicação e Expressão apresentou a maioria de seus índices com discriminação satisfatória. 
A consistência interna dos resultados da prova objetiva foi medida pelo coeficiente de fidedignidade de Kuder Richardson, para se conhecer qual porcentagem dos escores decorria de diferença verdadeira na capacidade medida. O resultado obtido foi de 0.81 , o que pode ser interpretado como significando que $81 \%$ da variância dos escores decorreu de diferenças verdadeiras na medida e $19 \%$ resultou de erros de medida.

\section{ANALISANDO A PROVA DE REDAÇÃo}

Em relação à prova de redação, os 373 candidatos da amostra dissertaram, em um espaço delimitado de 20 a 30 linhas, sobre o tema: "A Adolescência é ao mesmo tempo um fîm e um começo". O tema foi escolhido, dentre outros, pela amplitude da colocação e pela proximidade com a vivência e fase de desenvolvimento da maioria dos candidatos.

Antes de serem entregues aos professores, as redações foram limpas: as correções e as notas anteriormente atribuídas foram apagadas e somente foi mantido, na folha de redação, o número de inscrição do candidato, que passou a servir como código da prova para o presente trabalho. Antes de serem limpas foi feita uma cópia xerox de cada redação para que não se perdessem as primeiras correções. Os professores corretores não tiveram acesso nem ao nome e nem à área de opção do candidato.

Foram convidados três professores para corrigirem as redações selecionadas. Os três eram professores de português lecionando a disciplina há pelo menos 15 anos no segundo grau e pertenciam a equipe de correção de redação dos exames vestibulares da Fundação Carlos Chagas há, no mínimo, 5 anos. Neste sentido, estavam familiarizados com os critérios de avaliação usados pela Fundação e que haviam sido desenvolvidos por Vianna (1978) anteriormente. A única diferença em relação ao trabalho que estavam habituados a fazer foi a utilização de uma ficha de tabulação de erros para desconto da nota.

Cada professor corrigiu as provas individualmente e em um período mínimo de 15 dias e máximo de 25 dias. Antes de começarem a correção foram instruídos a respeito dos objetivos do trabalho, da 
utilização do critério e da ficha de avaliação. Eram também alertados para não fazerem marcas nas provas. Ao entregarem o trabalho pronto, cada professor relatava as dificuldades encontradas. Posteriormente, as redações eram revistas pelo pesquisador, antes deste entregá-las ao próximo avaliador, para verificar se traziam ou não quaisquer anotações.

\section{RESUltados}

A porcentagem de aprovação dos candidatos na prova de redação, tomando-se como "nota de corte" a nota cinqüenta, foi de $64.3 \%$, ou seja, 240 provas situavam-se acima da nota cinqüenta.

VIII- Freqüência das notas médias $\left({ }^{*}\right)$ atribuídas às redações pelos três professores corretores

\begin{tabular}{|c|c|}
\hline Intervalos & F \\
\hline $90-99$ & 5 \\
\hline $80-89$ & 24 \\
\hline $70-79$ & 41 \\
\hline $60-69$ & 79 \\
\hline $50-59$ & 91 \\
\hline $40-49$ & 68 \\
\hline $30-39$ & 32 \\
\hline $20-29$ & 18 \\
\hline $10-19$ & 14 \\
\hline $0-9$ & 1 \\
\hline Total & 373 \\
\hline
\end{tabular}

$\left.{ }^{(}\right)$Considera-se nota média a soma das notas atribuídas a uma prova dividida por três. 
$\mathrm{Na}$ atribuição de notas, a nota mínima foi zero e a máxima foi 93.5, o que define uma amplitude de variação de notas de 93.5 pontos. A média das notas médias do grupo foi 54.25 .

O nível de dificuldade da prova foi calculado, segundo estatística apresentada por Vianna (1984, p.73), isto é, comparou-se o desempenho dos sujeitos da amostra com o nível de desempenho mais alto possível. Assim, em termos operacionais, a dificuldade foi definida como a razão entre a diferença da média $(\mathbf{X})$ do grupo e o escore mais baixo possível ( $x$ min) - nível de desempenho - e a diferença entre o escore mais alto possível $(x \max )$ e o escore mais baixo possível ( $x$ min) - nível de desempenho mais alto possível, multiplicado por 100 para ser expresso em porcentagem. Para esta prova, o índice de dificuldade foi de 53.07, o que significa uma prova de dificuldade média para o grupo como um todo, confirmando os dados da tabela de freqüência de notas apresentada acima.

\section{ANÁLISE DA CORREÇÃo DAS PROVAS}

Analisando os dados apresentados na tabela abaixo, tem-se que as diferenças observadas indicam que houve variação na atribuição de notas pelos professores às mesmas redaçōes. IX-Médias e intercorrelações das notas atribuídas pelos três
professores corretores às $\mathbf{3 7 3}$ redações

\begin{tabular}{|c|c|ccc|}
\hline Professores & $\mathbf{X}$ & \multicolumn{3}{|c|}{ Intercorrelações } \\
& & P1 & P2 & P3 \\
\hline P1 & 54.71 & - & 0.72 & 0.63 \\
\hline P2 & 50.28 & - & - & 0.73 \\
\hline P3 & 57.22 & - & - & - \\
\hline
\end{tabular}

A possível flutuação de julgamentos entre professores remeteu ao cálculo das intercorrelações provavelmente existentes entre eles. Os índices obtidos $(0.63 ; 0.72$ e 0.73$)$ foram altos e sugeriram concordância entre os professores indicando, possivelmente, que eles não diferiam na avaliação das ređações, como levantado 
anteriormente, mas sim que avaliaram com diferentes graus de rigor. Esta concordância de julgamentos pode ser devida ao fato de os professores possuírem grande experiência de ensino ou estarem bastante familiarizados com os critérios de correção.

Partindo desta constatação decidiu-se calcular, pelo coeficiente de correlação produto-momento de Pearsons, a relação entre notas de redação e notas da prova objetiva.

\section{X- Intercorrelação entre as notas atribuídas pelos três professores e notas médias na prova de redação com as notas da prova objetiva}

\begin{tabular}{|c|c|c|c|}
\hline Avaliação & Prova Objetiva & F & $\begin{array}{c}\text { Intervalo de 95 \% } \\
\text { de confianca }\end{array}$ \\
\hline P1 & 0.44 & 9.62 & $0.36-0.52$ \\
\hline P2 & 0.51 & 11.46 & $0.43-0.58$ \\
\hline P3 & 0.54 & 11.72 & $0.46-0.61$ \\
\hline Nota Média & 0.56 & 13.22 & $0.49-0.63$ \\
\hline
\end{tabular}

As correlações obtidas e apresentadas na tabela acima, indicam que o professor $\mathrm{P} 3$ tem o índice mais alto de correlação de suas notas com as notas na prova objetiva e que também possui o índice (0.54) mais próximo do f́ndice das notas médias $(0.56)$. $O$ dado sugere que a correção deste professor poderia servir como correção-padrão.

A correlação entre nota média na redação e nota na prova objetiva foi de 0.56 que, apesar de não ser muito alta, não é suficiente para nos permitir afirmar que as duas provas mediram o mesmo conteúdo.

Decidiu-se continuar o estudo, procurando investigar o porquê do índice de correlação não ter sido maior. Levantou-se como possibilidade de explicação, a influência dos valores pessoais dos professores-avaliadores na atribuição de notas.

A tabela a seguir complementa e esclarece as anteriores. 
XI- Médias de cada professor corretor, nas três áreas de opção dos candidatos

\begin{tabular}{|c|c|c|c|}
\hline Prof & Ciências Biológicas & Ciências Exatas & Ciências Humanas \\
\hline & $\mathrm{X}$ & $\mathrm{X}$ & $\mathrm{X}$ \\
\hline P1 & 54.84 & 55.74 & 54.31 \\
\hline P2 & 53.84 & 50.53 & 47.76 \\
\hline P3 & 59.96 & 52.99 & 57.41 \\
\hline
\end{tabular}

Observando a média de cada professor na avaliação das redações tem-se que $\mathrm{P} 1$ é menos rigoroso no seu julgamento para com as redações dos candidatos à área de Ciências Exatas. P2 e P3 teriam o mesmo procedimento para com as redações da área de Ciências Biológicas. Isto nos sugere que, aparentemente, as redaçóes de uma área específica, que fossem atribuídas para serem corrigidas ao professor "mais generoso" na avaliação desta mesma área, teriam maior possibilidade de obter aprovação.

\section{Fidedignidade De RESUltados}

Tendo em vista os resultados obtidos, procurou-se saber a consistência dos dados obtidos na prova de redação, ou seja, a sua fidedignidade. A fidedignidade se relaciona com a estabilidade da medida no tempo e com a homogeneidade dos itens que compuseram a prova. No caso de uma avaliação que envolve grande grau de subjetividade, como é a correção de uma prova de redação, a homogeneidade é obtida através de acordo entre juízes.

Revendo a literatura na ârea de avaliação de conhecimentos, especificamente, a fidedignidade é descrita como sujeita a três influências principais: primeiro, diferentes professores tendem a assinalar diferentes notas a um mesmo trabalho, sendo que o grau de severidade na atribuição de notas é devido à utilização de diferentes padrões de correção e diferentes utilizações da escala de notas. Segundo, sabe-se que um avaliador tende a assinalar notas diferentes ao mesmo trabalho em ocasiōes diferentes e, por último, as diferenças 
entre as notas atribuídas tendem a aumentar conforme o tema ou questão da prova permitir maior liberdade de resposta.

Nos estudos sobre as provas com questōes dissertativas, como a redação, vários elementos que poderiam levar a uma distorção da nota obtida foram levantados e algumas destas perspectivas são apresentadas a seguir:

Eells (1930) preocupou-se com a variabilidade intra e interavaliadores no julgamento de um conjunto de provas, apos transcorrido um período de 11 semanas. Pelos dados obtidos, pode concluir que a recorreção não foi fidedigna, existindo falha no julgamento humano, mesmo quando o mesmo professor julga o mesmo material.

Chase (1968) investigou o efeito da caligrafia e o uso de uma "chave de correção" de questões abertas e concluiu que os avaliadores são generosos na atribuição de notas quando a prova é escrita em boa caligrafia. Avaliadores com provas de caligrafia ruim avaliam a primeira questão da mesma forma que avaliadores com provas de boa caligrafia. Mas, a partir da leitura da segunda questão, o efeito "halo" ou "auréola" da caligrafia ruim passa a influenciar a avaliação. Quanto à chave de correção, conclui que seu uso influencia o avaliador que passa a atribuir nota mais alta do que aquele que não a utiliza.

Marshall e Powers (1969) confirmam os dados de Chase, concluindo que provas com boa caligrafia recebem notas maiores.

Storey (1968), estudando a validade de questôes abertas (dissertativas) refere-se a Thorndike e Hagen para os quais estas questões testam a habilidade do estudante em selecionar, organizar e integrar idéias. As hipóteses de trabalho levantadas na literatura sugerem que, independentemente do conteúdo e do valor de uma resposta, os professores atribuem a mesma média "de passar"; usam a mesma amplitude da escala de notas e organizam uma distribuição simétrica ao redor da média escolhida. Portanto, concluem que na ausência de qualquer habilidade real para julgar o valor de uma resposta escrita, os professores atribuem notas para todos os alunos segundo um conjunto internalizado de valores e não segundo a capacidade real do aluno. $\mathrm{O}$ autor conclui que a questão aberta pode ser apropriada para medir a habilidade do estudante de escrever, mas não mais do que isto devido, principalmente, à inabilidade do 216 
professor em atribuir de notas levando a distorções na percepção de saber se o item realmente mede o que mede.

Marshall (1967) propôs-se a investigar a influência de erros gramaticais, de pontuação e de ortografia na nota atribuída por professores a uma redação. Também procurou investigar o quanto os professores estavam alertas para atribuir notas às redações somente pelo conteúdo, quando assim requisitado, em provas com erros de redação previamente introduzidos. Seus resultados indicam o quanto os professores eram influenciados pela apresentação da prova, mesmo quando deviam analisar somente o conteúdo. Relata que, desconsiderando o tipo de erro, parece haver uma tendência inversa entre o número de erros e a nota atribuída à prova. Professores com mais treino em conteúdo tendiam a dar notas mais severamente que professores com menos treino. Face a isso, concluiu que os professores são influenciados pela qualidade da composição de provas de questão aberta mesmo quando tentam atribuir notas em conteúdo.

Vianna (1976) estudando flutuações de julgamento na avaliação de 161 provas de redação afirma que as mesmas deveriam ser corrigidas por, no mínimo, três examinadores e que a nota atribuída deveria ser a média das três avaliaçōes para que se pudesse obter resultados fidedignos.

Em 1978, Vianna estudou uma amostra de provas de redação aplicando um critério pré-definido na correção das mesmas. Fazendo a análise de variância de 48 subconjuntos de notas, ele mostrou que existem diferenças significativas entre essas medidas, atribuindo essas diferenças à falta de homogeneidade na utilização dos critérios de correção pelos examinadores que empregaram critérios próprios, diferentes dos propostos. Concluiu, portanto,que a aplicação de um critério de correção de redação pela própria equipe que o definiu não garante a uniformidade dos resultados. Segundo ele, na correção de uma prova, os avaliadores diferem na nota atribuída mas concordam na posição relativa dela em relação às outras. Para ele, a variabilidade de julgamento é tão grande que a aprovação ou reprovação do estudante fica sujeita aos azares da sorte. Finalmente, coloca que a utilização de um número considerável de examinadores na correção de redações em concursos vestibulares exige treinamento dos docentes, 0 que, todavia, não garante correções isentas de influências individuais. 
Em outro estudo brasileiro, Bessa (1986) procurou verificar a fidedignidade de notas atribuídas à redação de concurso vestibular através da consistência de julgamento de diferentes juízes em relação às mesmas redaçōes. Tentando avaliar a diferença que existe entre as médias das notas atribuídas pelos professores-juízes a uma redação, conclui que a mesma deve-se, em parte, a diferenças entre julgamentos dos professores-juízes e, em parte, a erros residuais.

Coffman (1972) sugere que para reduzir a taxa de erro de uma avaliação, os professores-avaliadores deveriam usar uma escala de correção detalhada; desenvolver pontos de referência para apoiar a escala; distribuir o erro casualmente mais do que sistematicamente, avaliando questão por questão ao invés de candidato por candidato e, por último, que deveriam incluir classificações múltiplas quando possível.

A partir da ponderação da possível influência de todas as variáveis levantadas pela literatura na correção de provas analíticoexpositivas, decidiu-se realizar a análise de variância dos dados obtidos para aprofundar a questão da ocorrência da influência do fator professor (análise de variância oneway).

XII- Análise de variância das notas atribuídas por três professores-corretores, para as três áreas possíveis de opção do candidato

\begin{tabular}{|c|c|c|c|c|}
\hline $\begin{array}{c}\text { Fonte de } \\
\text { Variação }\end{array}$ & $\begin{array}{c}\text { Soma dos } \\
\text { Quadrados }\end{array}$ & $\begin{array}{c}\text { Grau de } \\
\text { Liberdade }\end{array}$ & $\begin{array}{c}\text { Quadrados } \\
\text { Médios }\end{array}$ & F\# \\
\hline $\begin{array}{c}\text { entre } \\
\text { professores }\end{array}$ & 10529.24 & 2 & 5264.62 & 38.58 \\
\hline entre candidatos & 369772.71 & 372 & 994.01 & 7.28 \\
\hline residual & 995023.50 & 744 & 136.44 & \\
\hline total & 1375325.46 & & & \\
\hline
\end{tabular}

$\# \mathrm{P} \leq 0.05$ 
Levando-se em consideração o fator professor e o fator aluno como fontes possíveis de variação influindo na atribuição de notas, tem-se que o primeiro fator obteve um índice de significância (38.58) muito maior que o segundo (7.28), o que confirma a possível influência do fator professor nesta variável.

Para esclarecer esta influência procurou-se verificar a variaçăo das notas atribuídas por área de opção dos candidatos, como mostra a tabela XIII.

\section{XIII- Análise de variância das notas atribuídas por três professores, para cada área de opção do candidato}

\begin{tabular}{|c|c|c|c|c|c|}
\hline $\begin{array}{c}\text { Fonte de } \\
\text { Variaçäo }\end{array}$ & Área & $\begin{array}{c}\text { Soma dos } \\
\text { Quadrados }\end{array}$ & $\begin{array}{c}\text { Grau de } \\
\text { Liberdade }\end{array}$ & $\begin{array}{c}\text { Quadrados } \\
\text { Médios }\end{array}$ & F\# \\
\hline entre & $\mathrm{B}$ & 3335.08 & 2 & 1667.54 & 12.12 \\
professores & $\mathrm{E}$ & 704.33 & 2 & 352.16 & 2.46 \\
& $\mathrm{H}$ & 8741.20 & 2 & 4370.00 & 33.87 \\
\hline entre & $\mathrm{B}$ & 152176.84 & 140 & 1086.97 & 7.90 \\
candidatos & $\mathrm{E}$ & 28716.07 & 51 & 563.06 & 3.93 \\
& $\mathrm{H}$ & 186622.57 & 179 & 1042.58 & 8.08 \\
\hline residual & $\mathrm{B}$ & 38496.07 & 280 & 137.48 & \\
& $\mathrm{E}$ & 14586.33 & 102 & 143.00 & \\
& $\mathrm{H}$ & 46183.96 & 358 & 129.00 & \\
\hline
\end{tabular}

\#P $\leq 0.05$

( $\mathrm{B}=$ Ciências Biológicas; $\mathrm{E}=$ Ciências Exatas; $\mathrm{H}=\mathrm{Ciências} \mathrm{Humanas)}$

Observe-se, nesta tabela, que na área de Ciências Exatas, a variação do fator candidato (3.93) ultrapassou a variação do fator professor na atribuição de notas (2.46). Nas demais áreas aconteceu o inverso.

O mesmo procedimento de análise de variância foi repetido tomando-se como variáveis a nota na prova objetiva e a nota média da prova de redação. Os resultados obtidos estão apresentados a seguir. 
XIV-Análise de variância da nota da prova objetiva e da nota média da prova de redação

\begin{tabular}{|c|c|c|c|c|}
\hline $\begin{array}{c}\text { Fonte de } \\
\text { Variacão }\end{array}$ & $\begin{array}{c}\text { Soma dos } \\
\text { Quadrados }\end{array}$ & $\begin{array}{c}\text { Grau de } \\
\text { Liberdade }\end{array}$ & $\begin{array}{c}\text { Quadrados } \\
\text { Médios }\end{array}$ & F\# \\
\hline $\begin{array}{c}\text { entre } \\
\text { professores }\end{array}$ & 12949.44 & 1 & 12949.44 & 95.37 \\
\hline $\begin{array}{c}\text { entre } \\
\text { candidatos }\end{array}$ & 191734.92 & 372 & 488.53 & 3.59 \\
\hline residual & 50508.54 & 372 & 135.77 & \\
\hline total & 245192.90 & 745 & & \\
\hline
\end{tabular}

$\# \mathrm{P} \leq 0.05$

De novo o fator professor aparece como altamente significante na atribuição de notas e este índice é ainda maior, indicando alta variação, quando a nota média de cada correção é comparada com a nota na prova objetiva.

XV-Análise de variância da nota da prova objetiva e da nota média da prova de redação, por área de opção do candidato

\begin{tabular}{|l|c|c|c|c|c|}
\hline $\begin{array}{l}\text { Fonte de } \\
\text { Variação }\end{array}$ & Área & $\begin{array}{c}\text { Soma dos } \\
\text { Quadrados }\end{array}$ & $\begin{array}{c}\text { Graus de } \\
\text { Liberdade }\end{array}$ & $\begin{array}{c}\text { Quadrados } \\
\text { Médios }\end{array}$ & F\# \\
\hline entre & $\mathrm{B}$ & 2358.87 & 1 & 2358.87 & 15.56 \\
professore & $\mathrm{E}$ & 1701.81 & 1 & 1701.81 & 11.47 \\
s & $\mathrm{H}$ & 9732.32 & 1 & 9732.32 & 83.40 \\
\hline entre & $\mathrm{B}$ & 79359.29 & 140 & 566.85 & 3.74 \\
candidatos & $\mathrm{E}$ & 13681.14 & 51 & 268.25 & 1.80 \\
& $\mathrm{H}$ & 84250.85 & 179 & 470.67 & 4.03 \\
\hline residual & $\mathrm{B}$ & 21211.78 & 140 & 151.51 & \\
& $\mathrm{E}$ & 7565.04 & 51 & 148.33 & \\
& $\mathrm{H}$ & 20888.14 & 179 & 116.69 & \\
\hline
\end{tabular}

$\# \mathrm{P} \leq 0.05$

Pelos dados da tabela, pode-se inferir que o fator professor e o fator candidato possuem os maiores índices de significância na área de Ciências Humanas e os menores na área de Ciências Exatas.

Todos os resultados apresentados pelas análises de variância indicam que os candidatos variaram menos na elaboração de suas redações, ou seja, eles provavelmente tiveram uma formação 
aproximada e um desempenho mais consistente do que o julgamento feito pelos professores sobre as mesmas redações.

Corroborando o já anteriormente discutido, o maior $\mathrm{F}$ obtido entre professores foi o da área de Ciências Humanas onde, possivelmente, o fator professor é mais marcante.

\section{ConClusōes}

O ponto de vista técnico, se é insuficiente para resolver as polêmicas que surgem a respeito do concurso vestibular, é necessário para esclarecer aspectos que podem influenciar linhas de ação e de tomada de decisão quanto ao mesmo.

O objetivo deste trabalho foi o de estudar o grau de interação (correlação) que existe entre duas formas de desempenho de candidatos às vagas na universidade: a prova objetiva e a prova de redação em Língua Portuguesa, pressupondo-se que avaliam o mesmo conteúdo.

Esta interação é analisada através da nota que o candidato recebeu em cada uma destas provas, estabelecendo-se como hipótese de trabalho ou nula, que esta correlação inexiste e que, portanto, a prova de redação é indispensável para avaliar o conhecimento e a utilização das normas cultas que regem a Língua Portuguesa, que não estariam sendo plenamente medidas pela prova objetiva.

Estudos semelhantes já foram realizados tanto em outros países quanto no Brasil e visaram a avaliar o emprego de um tipo de prova ou de outro para a tomada de decisão em situações dissemelhantes como as de sala de aula ou a de seleção de massa, como ocorre com o Concurso Vestibular.

Pelo f́ndice de correlação obtido no presente trabalho entre a prova objetiva e a nota média na prova de redação $(0.56)$ não se pode afirmar, categoricamente, que a prova de redação é dispensável do processo seletivo por medir o mesmo conhecimento que a prova objetiva já mediu. $\mathrm{O}$ índice necessitaria ser mais alto para que tal afirmação pudesse ser feita. Ao mesmo tempo ele não é baixo o suficiente para que se pudesse afirmar que a redação é absolutamente indispensável. Aquele índice somente nos permite afirmar que ela talvez fosse dispensável se fatores intervenientes, como a forma de 
correção, fossem controlados, dado que as análises de variância realizadas indicam a influência do fator professor na atribuição de notas.

Os professores avaliadores convidados a participar da pesquisa tinham experiência como professores de segundo grau e como avaliadores de provas de redação em Concurso Vestibular. Mesmo assim os dados obtidos indicam que, apesar de haver alguma consistência entre as correções realizadas, os avaliadores diferiram quanto ao grau de severidade com que atribuíram as notas.

Para controlar o "fator professor" na avaliação de provas de redação em Concursos Vestibulares, certos cuidados devem ser tomados, desde a seleção dos professores avaliadores que devem ter experiência no ensino de segundo grau, até o treinamento destes professores em como controlar a sua própria avaliação (discussão do tema proposto e estabelecimento de idéias básicas, utilização dos critérios de seleção preestabelecidos e utilização da escala de notas em toda a sua amplitude). Alguns autores sugerem que a correção deste tipo de prova deveria ser feita abrangendo, em primeiro lugar, o tipo de correção baseado na primeira impressão que a redação causou ao professor, separando-se as redações em cinco blocos e, em segundo lugar, corrigindo-se cada um dos blocos separadamente, de acordo com critérios pré-definidos.

Além do treinamento é importante utilizar três ou mais professores na correção de cada prova, de tal forma que a nota do candidato seja dada pela nota média das notas atribuídas pelos professores, o que aumentaria a estabilidade do julgamento.

Precauções também devem ser tomadas sabendo-se que estudos sobre a prova de redação indicam que variáveis não diretamente relacionadas à formação do aluno, como fatores socioeconômicos e culturais, intervêm no processo de avaliação, na forma de um currículo oculto.

A tendência descrita na literatura e que também surgiu na pesquisa em foco, de os professores julgarem as provas de redação com diferente grau de generosidade na atribuição de notas para provas de diferentes áreas, mesmo não conhecendo a área de opção do candidato, é um ponto extremamente instigante a ser aprofundado em 
novas pesquisas, principalmente pelas áreas de medidas educacionais e psicologia cognitiva.

Esta experiência, conjuntamente com a tendência de generosidade de atribuição de notas demonstrada por professores avaliadores de questões analítico-expositivas levam ao questionamento de como se dá a construção do conhecimento, ou se este padrão de construção do conhecimento preexiste e direciona a uma escolha vocacional.

Questões como estas somam-se a outras, como por exemplo, tendo o processo inteiro controlado tecnicamente, desde a construção da prova objetiva até a correção da prova analítico-expositiva, qual das duas provas seria o melhor preditor do desempenho acadêmico?

$\mathrm{O}$ trabalho apresentado dá uma contribuição pontual à questão do vestibular. Ele deve se somar a outros estudos que discutem o próprio processo avaliativo do desempenho de estudantes, vivido no primeiro e segundo graus de ensino, com toda a complexidade que o caracteriza, incluindo-se, também, a discussão sobre a insuficiência da formação e do treinamento de professores para acompanhar o processo de formação do conhecimento do aluno, a partir de indicadores da aprendizagem mais consistentes e básicos.

Finalmente, deve-se ressaltar que existem diferenças significativas entre avaliação na escola e avaliação em exame vestibular. Enquanto a primeira acompanha e orienta um processo de aprendizagem e considera cada medida um indicador de necessárias intervenções na prática pedagógica, o Concurso Vestibular assume-se como um instrumento que mede o processo de uma maneira diferente, ou seja, pelo conhecimento já adquirido e sedimentado, em um momento determinado da vida estudantil.

As provas de redação ou provas analítico-expositivas em qualquer área, quando usadas em sala de aula, têm uma função específica no processo de avaliação da aprendizagem. Todavia, quando usadas como instrumento para seleção de um grande número de candidatos, em uma situação diferente da conhecida por eles na escola e de cujo resultado depende uma definição profissional, deveriam ser repensadas e melhor estudadas para se obter resultados mais consistentes. 
A análise apresentada neste trabalho, apesar de ser basicamente técnica, levanta hipóteses e possibilidades de explicação que só se realizam e se completam em relação à realidade social em que se insere. A ênfase nesta relação esteve subjacente a todo o trabalho para esclarecê-lo e completá-lo.

\section{REFERÊNCIAS BIBLIOGRÁFICAS}

BESSA, Nícia Maria Fidedignidade de notas atribuídas a redações: enfoque teórico e empírico. Educação e Seleção, São Paulo: Fundação Carlos Chagas, $\mathrm{n}^{\circ}$ 14, p.25-46, jul.dez. 1986.

CHASE, Clinton I. The Impact of some obvious variables on essay test scores. Journal of Educational Measurement, v. 15, $\mathrm{n}^{0} 4, \mathrm{p}$. 315-8, winter 1968.

COFFMAN, William E. On the reliability of ratings of essay examinations in english.In: Research in the teaching of english, v.5, $\mathrm{n}^{\circ} 1$, spring 1971.

DI DIO, R. A. T. Testes objetivos versus provas analíticodissertativas no vestibular da Fuvest, 1977. Estudos e Documentos, São Paulo: Faculdade de Educação, USP, 1978.

EELLS, Walter Crosby. Reabiality of repeated grading of essay type examinations. Journal of Educational Psychology, v. 21, $\mathrm{n}^{\circ} 1$ 1930.

HOFFMAN, J. M. L. A controvérsia da redação no vestibular: questão de pertinência da prova ou de fidedignidade de medida? Educação e Seleção, São Paulo: Fundação Carlos Chagas, $n^{\circ}$ 17, p. 115-28, jan.jun. 1988.

LELIS, I. A. O. M. Evolução histórico-legal do vestibular (19681983): do milagre à recessão. Educação e Seleção, São Paulo: Fundação Carlos Chagas, $\mathrm{n}^{\circ} 12$, p. 27-45, jul.dez. 1985.

MARSHALL, Jon C. Composition errors and essay examination grades reexamined. American Educational Research Journal, v. $4, n^{\circ} 4$, p. 375-85 1967.

MARSHALL, Jon C.; POWERS, Jerry M. Writing neatness composition errors and essay grades. Journal of Educational Measurement, v.16, $\mathrm{n}^{\circ} 2$, summer 1969. 
MONTEIRO, Fernando Borges Moreira. Compilador: legislação referente ao concurso vestibular. Fundação Edson Queiroz; Universidade de Fortaleza, set. 1990.

MORAES, L. C. D. Mudança nos vestibulares de comunicação e expressão. Educação e Seleção. São Paulo: Fundação Carlos Chagas, $\mathrm{n}^{\circ} 15$, p. 77-82, jan .jun. 1987.

ROCCO, Maria Thereza Fraga Crise na linguagem: a redação no vestibular. São Paulo: Mestre Jou, 1981.

SIMS, Verner Martins The objectivity, reliability and validity of an essay examination graded by rating. Journal of Educational Research, v.24, p. 212-23, jun.dec. 1931.

STOREY, Arthur G. Some evidence in the essay item case. The Journal of Educational Research, v. 61, n 8, apr. 1968.

VIANNA, Heraldo Marelim Acesso à universidade: os caminhos da perplexidade. Educação e Seleção. São Paulo: Fundação Carlos Chagas, $n^{\circ} 14$, p. 87-132, jul. dez. 1986.

Acesso à universidade: um estudo de validade. Educação e Seleção, São Paulo: Fundação Carlos Chagas, $n^{\circ} 15$, p. 83-143, jan .jun. 1987.

Aplicação de critérios de correção em provas de redação. Cadernos de Pesquisa, São Paulo: Fundação Carlos Chagas, $n^{\circ}$ 26, p. 29-34, set. 1978.

- Avaliação Educacional: algumas medidas precursoras. Educação e Seleção, São Paulo: Fundação Carlos Chagas, n 6, p. 63-70, jul.dez. 1982.

. Comunicação e expressão: problemas teóricos e práticos de avaliação. São Paulo, IBRASA, 1984.

. Flutuações de julgamentos em provas de redação. Cadernos de Pesquisa. São Paulo: Fundação Carlos Chagas, $\mathrm{n}^{\circ} 19$, p. 5-9, dez. 1976.

Medida de expressão escrita e prova objetiva: um estudo preliminar de validade. Cadernos de Pesquisa, São Paulo: Fundação Carlos Chagas, n 38, p. 26-44 1981.

Natureza das medidas educacionais. Educação e Seleção, São Paulo: Fundação Carlos Chagas, n9, p. 7-16, jan. jun. 1984. 
A perspectiva das medidas referenciadas a critérios. Educação e Seleção, São Paulo: Fundação Carlos Chagas, n², p. 5-14, jul.dez. 1980.

Redação e Medida da expressão escrita: algumas contribuições de pesquisa educacional. Cadernos de Pesquisa, São Paulo: Fundação Carlos Chagas, n 16, p. 41-7, mar. 1976. 